\title{
Foveal light-detection thresholds with two temporally spaced flashes: A review
}

\author{
ROBERT M. HERRICK \\ Naval Air Development Center, Warminster. Pennsylvania 18974
}

\begin{abstract}
The literature on the interaction of two successive identical subliminal flashes in determining the light detection threshold is reviewed. Four empirical equations, collectively termed the TEpee effect, give a good description of the data of several studies. The TEpee effect describes detection data obtained with several background luminances, with a variety of flash durations, with different colors, with decrements as well as with increments (flashes), and with both monocular and binocular viewing. The TEpee effect also describes detection data obtained with multiple identical flashes, with two electrical pulses (phosphene threshold), with response latency measures, with critical flicker frequency, and, possibly, with the interaction of two supraliminal flashes. The TEpee effect is limited to identical flashes presented foveally. It does not describe the interaction of nonjdentical flashes, nor does it describe the interaction of flashes in the peripheral retina.
\end{abstract}

This paper reviews experiments in which two identical flashes, each by itself subliminal, are presented foveally to determine the light detection threshold as a function of the interval between the flashes. To facilitate comparisons, the data were read from the plots given in the experiments and replotted in a common piot, a $\log \cdot \log$ plot of total threshold energy, E, as a function of total display time, $T$. (These terms, $E$ and $T$, will be defined in the next section.) This particular plot was chosen because, in such a plot, data of two studies (Herrick, 1972, 1973a) were well described by simple visual laws that are represented by four straight lines.

In addition to the light-detection studies, the review includes other studies in which two or more identical stimuli were presented, namely, studies of response latency, of brightness comparisons, of critical flicker frequency, and of phosphene thresholds.

\section{DESCRIPTION OF TERMS AND PROCEDURES}

Figure 1 describes the experimental situation. To a background luminance, $I$, are added two identical subliminal flashes, separated by an interval, $i$; each flash has a duration, $t$, and a luminance, $\Delta \mathrm{I}$. The total time of the display equals $(t+i+t)$, or $T$. When the two flashes are added to the background luminance, $O$ responds "Yes" ("I detected a change") or "No" ("I did not detect a change"). When the interval, $i$, is short, the two flashes, when seen, are perceived as one.

Two data collection procedures are used. One procedure is to maintain constant the flash duration, $t$, and, at each interval, $i$, determine the threshold $\Delta I$ luminance. The other procedure is to maintain constant the $\Delta I$ luminance and, at each interval, $i$, determine the threshold duration of $t$.

Using either of these procedures, the total threshold energy, E, provided by the two identical flashes is defined as

$$
\mathrm{E}=2 \mathrm{t} \Delta \mathrm{I}
$$

With $t$ in milliseconds and $\Delta \mathrm{I}$ in millilamberts, the units of $\mathrm{E}$ are millilambert milliseconds. Also, the threshold average luminance, $A_{L}$, provided by the two flashes during the total display time, $\mathrm{T}$, is defined as

$$
A_{L}=E / T \text {. }
$$

With $E$ in millilambert milliseconds and $T$ in milliseconds, the units of $A_{L}$ are millilamberts.

\section{LOG T vs LOG E PLOT}

As mentioned above, the data of each study were replotted, in a $\log -\log$ plot, with threshold energy, E, as a function of total display time, T. Figure 2 illustrates such a plot. The four straight lines of Fig. 2 were based on data obtained with a flash duration of $5 \mathrm{msec}$, and with $\Delta \mathrm{I}$ varied to obtain a threshold at each of several

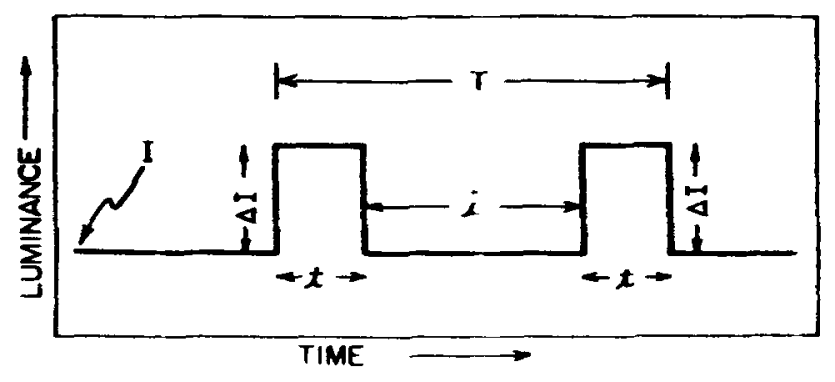

Fig. 1. Definitions of symbols used to summarize experimental procedures and results. I = background luminance; $t=$ flash duration; $i$ = interval between flashes; $\Delta I=$ flash luminance; $T=$ total display time. 


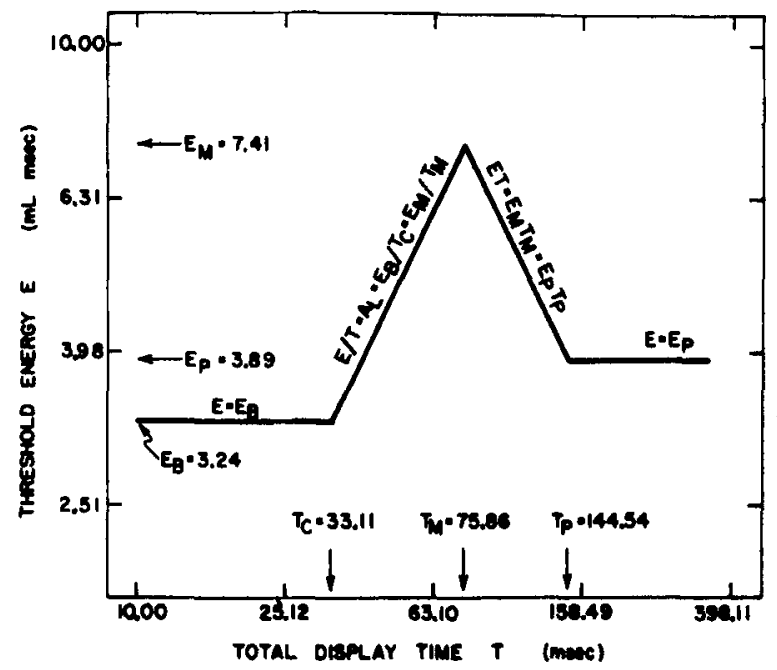

Fig. 2. Threshold energy, $E$, as a function of total display time, T, on a $\log -\log$ plot. Vertical markings spaced by $0.2 \mathrm{log}$ unit; horizontal markings spaced by $0.4 \mathrm{log}$ unit. The slopes of the four lines are $0.0,+1.0,-1.0$, and 0.0 . Lines based on two-flash data (Herrick, 1972) obtained with background luminance $I=1.02 \mathrm{~mL}$; flash duration $t=5 \mathrm{msec}$. (TEpee plot.)

intervals between the two flashes (Herrick, 1972). Collectively, the four straight lines, or the equations of the four lines, have been termed the TEpee effect, and the plot of $\log \mathrm{T}$ vs $\log \mathrm{E}$ has been called a TEpee plot (Herrick, 1972, 1973a).

In Fig. 2, the points of intersection of the lines are designated by the symbols; e.g., the point of intersection of the first two lines is given by the coordinates $\left(\mathrm{T}_{\mathbf{C}}, \mathrm{E}_{\mathbf{B}}\right)$. Reading from left to right, the slopes of the four straight lines are $0.0,+1.0,-1.0$, and 0.0 . The equations of the lines are given in Fig. 2 . The first line indicates that the threshold energy equals a constant, $E_{B}$, at all intervals from $0.0 \mathrm{msec}$ up to a critical interval. This critical interval, $23.11 \mathrm{msec}$ in Fig. 2, is the interval of the total display time, $T_{C}$. Following $T_{C}$, as the interval increases, threshold energy increases, following the rule that the threshold average luminance, $A_{L}$, remains constant and equal to $E_{B} / T_{C}$ or $E_{M} / T_{M}$. The energy increase continues until the maximum threshold energy, $E_{M}$, occurs at time $T_{M}$. Following $T_{M}$, threshold energy decreases according to the law ET = constant, until time $T_{P}$ is reached. Thereafter, threshold energy equals $E_{p}$, a constant.

The increase in threshold energy from $E_{B}$ to $E_{M}$ represents more than a doubling of threshold energy. This means that, to achieve threshold at $T_{M}$, the $\Delta I$ luminance required for each of the two $5-\mathrm{msec}$ flashes is greater than the $\Delta I$ luminance required for a single 5-msec flash. [Many other details of the TEpee effect may be found in earlier reports (Herrick, 1972, 1973a).]

\section{REVIEW OF TWO-FLASH STUDIES}

The data from which the TEpee effect was derived are presented in several plots in Herrick's (1972) report. The first row of Table 1 summarizes the conditions of that experiment. The lines of Fig. 2 represent fits to the data of only one session of that study, at one background luminance. The TEpee effect, however, described the data at all background luminances, from 0.05 to $66 \mathrm{~mL}$. As the background luminance increased, the TEpee function was displaced upward, to higher threshold energies, and to the left, so $T_{C}, T_{M}$, and $T_{p}$ decreased.

Figure 3 presents sample data of four other experiments, and Table 1 summarizes the experimental conditions. The two uppermost plots in Fig. 3 represent light detection thresholds. The third plot represents a case of two decrements, rather than two increments (flashes); i.e., luminance was subtracted from, rather than added to, the background luminance. [Other studies (Ikeda, 1965; Rashbass, 1970) also report that two decrements give the same results as two increments.] The lowest plot in Fig. 3 represents an experiment on the phosphene threshold. In this study, O's task was to report seeing light when the eye was stimulated not by light flashes but by two identical

Table 1

Summary of Experimental Conditions of Two-Flash Foveal Experiments

\begin{tabular}{|c|c|c|c|c|c|c|c|c|c|}
\hline \multirow[b]{2}{*}{ Author } & & \multicolumn{3}{|c|}{ Background Field } & \multicolumn{2}{|c|}{ Test Field } & \multicolumn{2}{|c|}{ Flash } & \multirow{2}{*}{$\begin{array}{c}\text { Figu re } \\
\text { Refer- } \\
\text { ence }\end{array}$} \\
\hline & & Size* & Luminance & Color & Size* & Color & $\begin{array}{c}\text { Duration } \\
\text { (msec) }\end{array}$ & $\begin{array}{l}\text { Lumi- } \\
\text { nance }\end{array}$ & \\
\hline Herrick, 1972 & $\mathbf{M}$ & $1^{\circ} z^{\prime}$ & 0.05 to $66 \mathrm{~mL}$ & White & $1^{\circ} 7^{\prime}$ & White & 5.0 & Varied & 2 \\
\hline Herrick \& Theisen, 1972 & M & $1^{\circ} 7^{\prime}$ & $0.11 \& 1.19 \mathrm{~mL}$ & White & $1^{\circ} 7^{\prime}$ & White & Varied & Constant & 3 \\
\hline Ikeda, 1965 & $\mathbf{M}$ & & $61.2 \& 328 \mathrm{td}$ & $630 \mathrm{~nm}$ & $30^{\prime}$ & $630 \mathrm{~nm}$ & 12.5 & Varied & 3 \\
\hline Schuckman \& OTbach, 1965 & B & $26^{\circ} \times 42^{\circ}$ & $18 \mathrm{~mL}$ & White & $15^{\prime}$ & - & Varied & Zero & 3 \\
\hline Baumgardt \& Bujas, 1951 & & & Phosphene Thr & eshold & & & 3.4 & Varied** & 3 \\
\hline Uetsuki \& Ikeda, 1970 & $\mathbf{M}$ & $6^{\circ}$ & 0 to 302 td & $630 \mathrm{~nm}$ & $30^{\prime}$ & $630 \mathrm{~nm}$ & 10.0 & Varied & 4 \\
\hline Clark, 1958 & B & $25^{\circ} \times 25^{\circ}$ & $0 \& 10 \mathrm{fL}$ & $2600^{\circ} \mathrm{K}$ & $18^{\prime}$ & White & 2.5 & Varied & 4 \\
\hline Rashbass, 1970 & $\mathbf{M}$ & $17^{\circ}$ & $700 \mathrm{td}$ & $555 \mathrm{~nm}$ & $17^{\circ}+$ & $555 \mathrm{~nm}$ & 2.0 & Varied & 4 \\
\hline Roufs, 1973 & $\mathbf{M}$ & $1^{\circ}$ & 1 to 1200 td & White & $1^{\circ}$ & White & 2.0 & Varied & 4 \\
\hline Herrick, $1973 \mathrm{a}$ & $\mathbf{M}$ & $1^{\circ} 7^{\prime}$ & 0.1 to $45 \mathrm{~mL}$ & White & $1^{\circ} 7^{\prime}$ & White & 5.0 & Varied & 5 \\
\hline Tittarelli \& Marriott, 1970 & $\mathbf{M}$ & - & $0 \mathrm{~mL}$ & Black & $1^{\prime}$ & $550 \mathrm{~nm}$ & 1.4 & Varied & - \\
\hline
\end{tabular}

Note $-M=$ monocular, $B=$ binocular

**Two electrical pulses with the current varied.
*Diameter of disk, unless otherwise noted; specified as visual angle.

tThis test field extends, of course, beyond the limits of the fovea. 
electrical pulses. The threshold current was determined as a function of the interval between the two pulses. Another phosphene study (Howarth, 1954) reports similar results.

Sample data of four other light-detection experiments are given in Fig. 4. The top plot of Fig. 4 shows that deviations from the TEpee lines occur at the points of intersection. The data points of this plot represent averaged data of three to five sessions, and, as pointed out in previous publications (Herrick, 1972, 1973a), averaging data of different sessions distorts the shape of the TEpee function.

In the second plot of Fig. 4, each data point was derived from a different session. As these data indicate, session-to-session variability so complicates the picture that no clear-cut relationships emerge. [The data reported by Blackwell (1963) are those he obtained with Clark, some of which are shown in this second plot of Fig. 4. Apparently, in his presentation (1963, Fig. 53), Blackwell, in some unspecified way, combined not only the data of several sessions, but also the data of two Os. Thus, the criticism on averaging, mentioned above, also applies to Blackwell's plot.]

The third plot from the top in Fig. 4 is included, although, unlike the others, the test field used in this study extended well beyond the fovea (see Table 1). This plot and the lowest plot of Fig. 4, Rouf's data, are both reasonably well described by the TEpee effect.

The data of Tittarelli and Marriott's (1970) study (see Table 1) apparently deviate from the TEpee description. In their study, relative log threshold energy increased from 0.0 to only 0.22 , as the interval between the two flashes was varied from 0 to $60 \mathrm{msec}$; then, at $i=$ $80 \mathrm{msec}$, the log threshold energy remained as it was at $60 \mathrm{msec}$. In this study, however, as in some of the others reported above, the results were based on the data of several sessions combined.

The above review indicates that the four equations of the TEpee effect provide a good description of data of many two-flash studies. The description holds for a wide range of background luminances, for backgrounds and test fields of a variety of sizes, for flashes of various durations and various colors, for decrements as well as for increments (flashes), and for monocular and binocular viewing. Where deviations from the TEpee effect do occur, the deviations are probably the result of combining data of different sessions or of different Os.

\section{PROBABILITY OF "YES" AS A FUNCTION OF THE INTERVAL}

In the studies reviewed above, the two-flash data were plotted in TEpee plots, which require threshold measures. Because the data-collection method of Van den Brink and Bouman (1954) provided no threshold measure, their study was omitted from the preceding review. In the Van den Brink and Bouman study, two identical $10-\mathrm{msec}$ flashes of constant $\Delta \mathrm{I}$

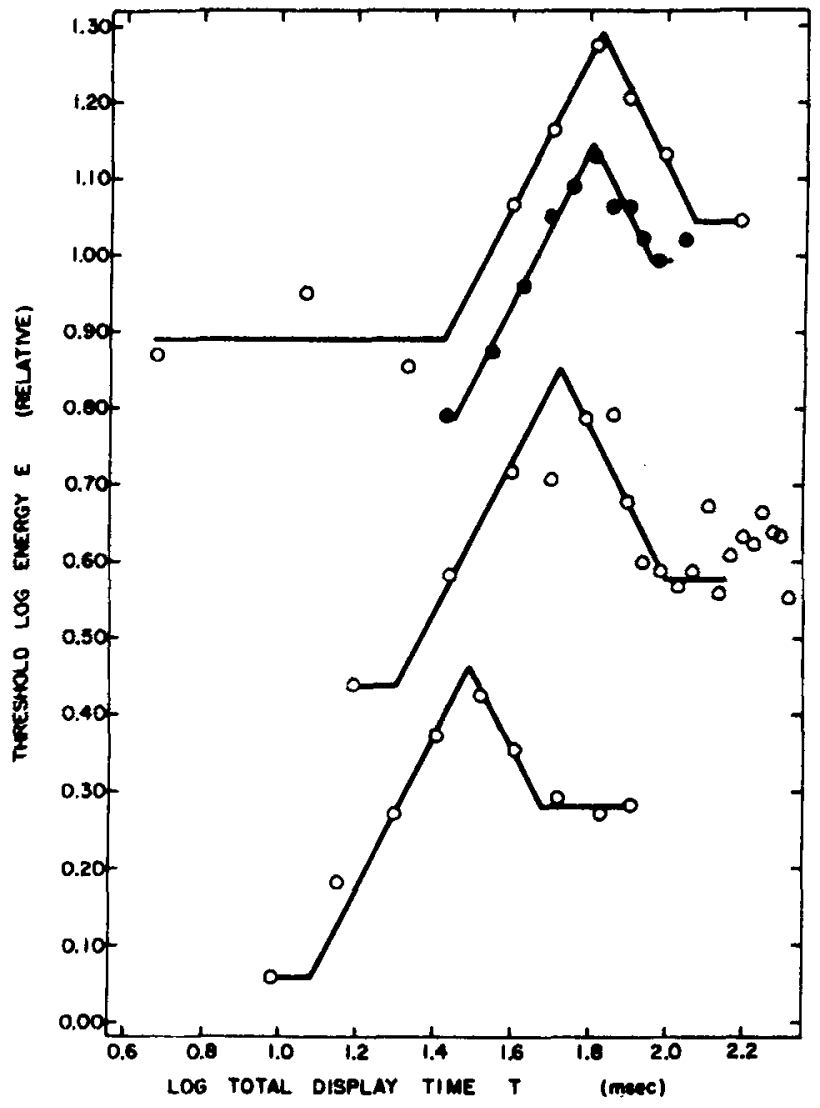

Fig. 3. TEpee plots of four studies. From top to bottom, the four plots represent sample data from Herrick \& Theisen (1972), Ikeda (1965), Schuckman \& Orbach (1965), and Baumgardt \& Bujas (1951). (See Table 1 and text.)

luminance were presented to 0 , and the proportion of "Yes" responses, $p$, was determined as a function of the interval between the flashes (see Fig. 1). Thus, Van den Brink and Bouman's data-collection procedure yielded a plot ${ }^{1}$ of $p$ as a function of $i$. Their $p$ vs $i$ plot indicated that, at short intervals, $p$ remained constant and equal to about 0.80 ; then, as the interval increased, $p$ decreased systematically to 0.50 ; then, as the interval increased further, $p$ remained equal to 0.50 .

Do these findings of Van den Brink and Bouman agree with what one would expect on the basis of the TEpee effect? To answer this question, the relationship between the TEpee effect and the $p$ vs i function must be derived; that is, assuming that the relationships summarized in the TEpee plot are valid, how should $p$ vary with $i$ ? Because of the many steps required to provide a suggested solution to this problem, the analysis is given in an appendix. The analysis indicates that the TEpee plot of Fig. 8 (in the appendix) should yield the $p$ vs i plots of Fig. 10. Clearly, the predictions of the $p$ vs $i$ relationship of Fig. 10 are in disagreement with the findings of Van den Brink and Bouman.

Since the TEpee effect gave a good description of several studies (see review above), it seemed unlikely 


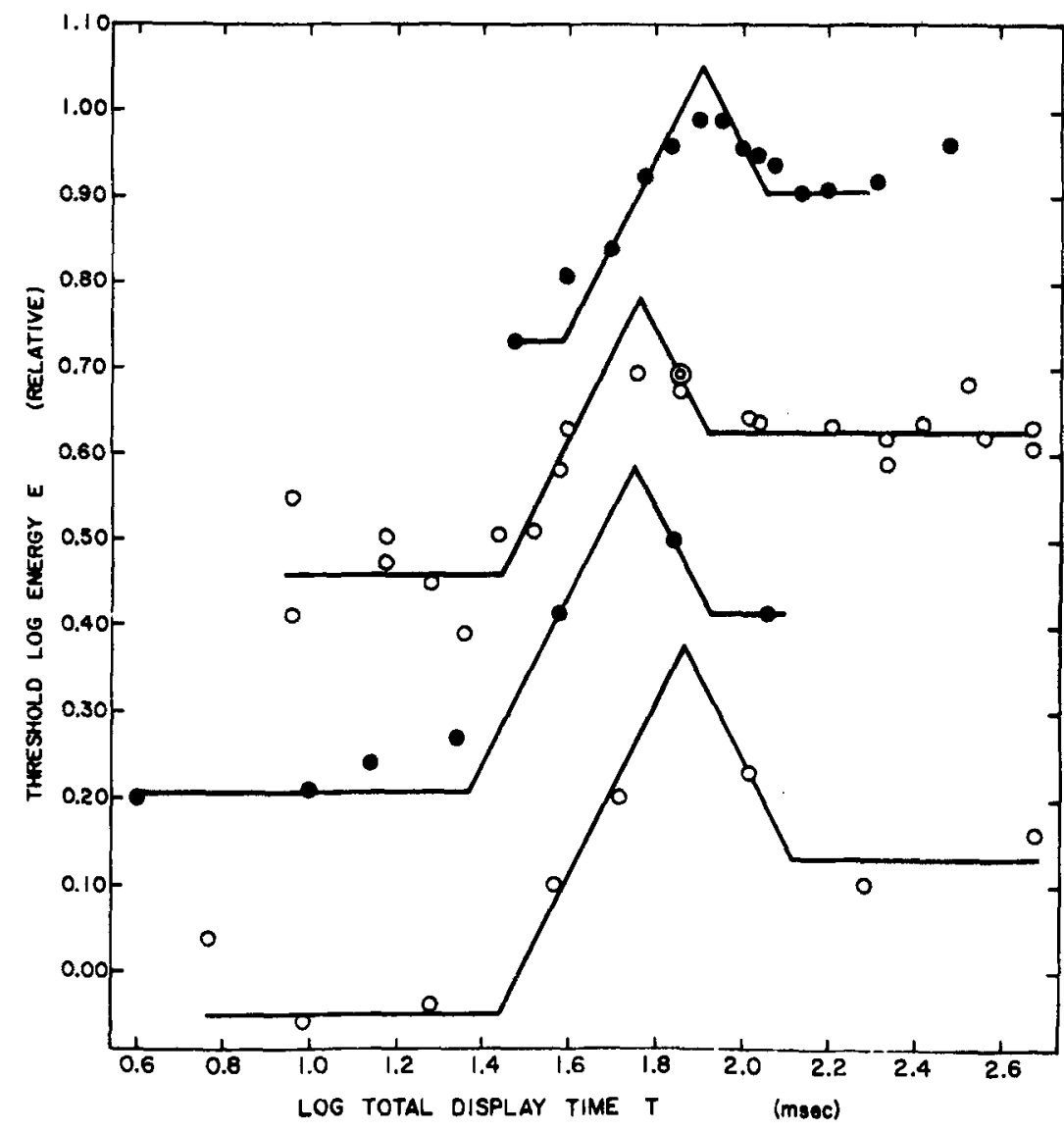

Fig. 4. TEpee plots of four studies. From top to bottom, the four plots represent sample data of Uetsuki \& Ikeda (1970), Clark (1958), Rashbass (1970), and Roufs (1973). that the TEpee effect was invalid, at least as a first approximation to the real world. The steps followed in deriving the predictions could be in error, however. Or the experiment of Van den Brink and Bouman could differ, in some critical aspect, from the experiments on which the TEpee effect was based. Analysis, however, revealed no suitable candidate for the cause of the difference. In any case, to shed some light on the disagreement, the decision was made to collect some new two-flash data, using the data-collection procedure of Van den Brink and Bouman.

\section{EXPERIMENTAL EVALUATION OF PREDICTIONS OF $p$ vs i}

With a constant $\Delta \mathrm{I}$ luminance, the proportion of "Yes" responses, $p$, was determined as a function of the interval, $i$, between the two identical flashes. The $O$ was first dark adapted for $5 \mathrm{~min}$. Then, for $5 \mathrm{~min}$, $O$ was light adapted to a centrally fixated field of white light, in the form of a disk, $1 \mathrm{deg} 7 \mathrm{~min}$ of visual angle in diam, with a luminance, $I$, of $1.19 \mathrm{~mL}$. To the entire 1-deg 7-min field, two 5-msec flashes of white light of $0.30 \mathrm{~mL}$ were added, at each of eight intervals, namely, $5,20,35,50,65,80,95$, and $110 \mathrm{msec}$. The intervals were presented in random order until a total of 25 ("Yes" and "No") judgments were obtained at each interval.
The results of two sessions, given in Fig. 5 , indicate that the shapes of the $p$ vs $i$ function obtained experimentally are in agreement with the predictions represented in Fig. 10. The intervals at which $p$ is at a

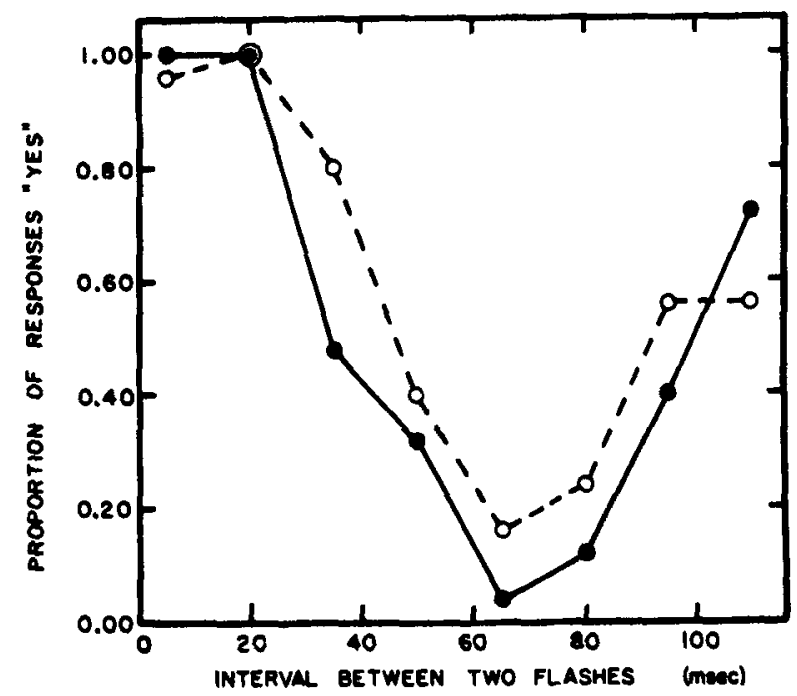

Fig. 5. Proportion of "Yes" responses as a function of the interval between two 5 -msec flashes. Background luminance $I=$ $1.19 \mathrm{~mL} ; \log \Delta \mathrm{I}(\mathrm{mL})=-0.52$. Each curve gives the data of one session; each point is based on 25 "Yes"-."No" judgments. Observer A.L. 
minimum differ in Figs. 5 and 10 because the background luminances differ. In both cases, the interval at which $\mathrm{p}$ is a minimum corresponds to the interval requiring the maximum energy in an experiment in which a threshold is determined.

As mentioned in the appendix, a plot of $p$ vs i may be transformed to a TEpee plot. Figure 6 shows the Fig. 5 data transformed to TEpee plots. In these transformations, the three $p$ valuesof 1.00 in Fig. 5 were taken as $p=0.96$, that is, as if one of the 25 "Yes" responses were "No." This approximation was introduced because a $\mathrm{p}$ of 1.00 does not exist in a cumulative normal distribution. Also, the standard deviation of the psychometric function was taken as $0.12 \log$ units for the upper curve and as $0.10 \log$ units for the lower curve of Fig. 5 (see Appendix).

\section{OTHER STUDIES DESCRIBED BY THE TEpee EFFECT}

It was noted that, in addition to the two-flash studies, experiments on the phosphene threshold are described by the equations of the TEpee effect. Do the equations describe the data of any other experiments? Yes, as Fig. 7 illustrates, data obtained with $2,3,6,12$, or 100 identical flashes are described by the equations. [In Fig. 7, $E=n t \Delta I$, and $T=n t+(n-1) i$, where $n$ is the number of 5-msec flashes.] And, presumably, data obtained with any number of identical flashes will be described by the TEpee equations.

In the experiment with 100 identical flashes (Fig. 7), the luminance of the field fluctuated between $I$ and $(\mathrm{I}+\Delta \mathrm{I})$, and O's task was to detect any change in the luminance of the field. This procedure is identical with the procedure followed in experiments typically termed critical flicker frequency (CFF) experiments. The conclusion, therefore, is that the equations of the TEpee

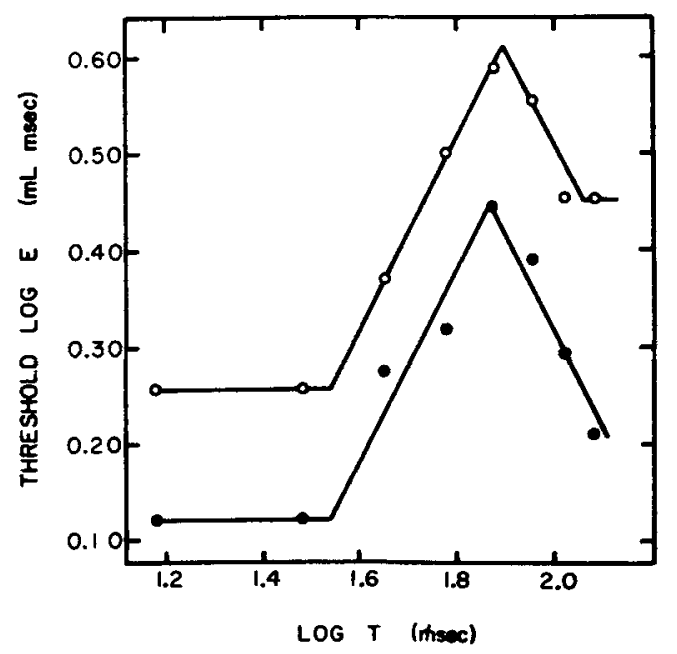

Fig. 6. TEpee plots based on the data of Fig. 5. For clarity, the lower curve is displaced downward from its true location by $0.2 \log$ unit.

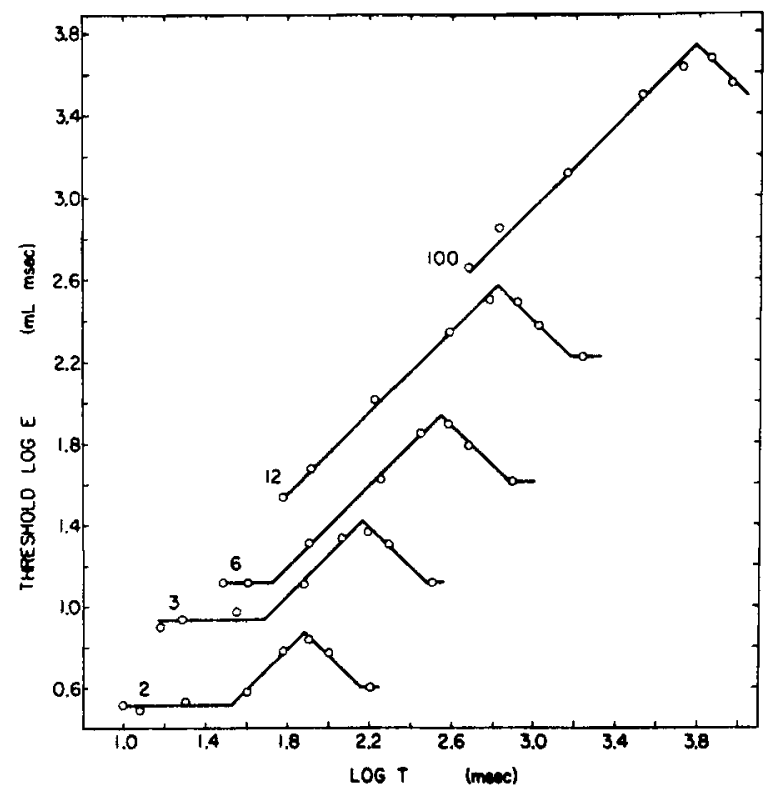

Fig. 7. Threshold $\log$ energy as a function of $\log$ total display time. $E$ is the total threshold enengy $(E=n t \Delta I)$ provided by the flashes, and $\mathrm{T}$ is the time from the beginning of the first flash to the end of the last flash. The number next to each curve gives the number of 5 -msec flashes. For clarity, the curves for $3,6,12$, and 100 flashes have been displaced upward by $0.3,0.6,0.9$, and $1.2 \mathrm{log}$ units, respectively. Background luminance of $1.02 \mathrm{~mL}$. The first point of each curve represents an interval i of 0 msec. (Herrick, 1973a.)

effect also provide a good description of CFF experiments.

The data of some visual studies cannot be evaluated quantitatively by the equations of the TEpee effect. Nevertheless, qualitative comparisons are possible. In Grossberg's study (1970), a dark-adapted $O$ released a microswitch as soon as he detected a light, when the light was presented by two identical flashes. The interval between the two flashes was the independent variable; the latency, namely, the time between the onset of the first flash and the release of the microswitch, was the dependent variable. At short intervals, the median latency was constant. Then, as the interval increased, latency increased gradually until it was greater than the latency for a single flash. As the interval increased still further, latency decreased. These changes in latency, as a function of the interval, reflect what one would predict on the basis of the TEpee effect.

Baumgardt and Segal $(1942,1946)$ presented two identical, supraliminal, 10-msec flashes. The first flash illuminated a 1.5-deg square; the second illuminated a 3.5-deg square, concentric with the first. Thus, the central 1.5-deg square received the light of both flashes, while the surrounding frame received only the light of the second flash. When the flashes were presented simultaneously, the center appeared brighter than the frame. As the interval between the flashes was increased. the center approached the brightness of the frame, and, 


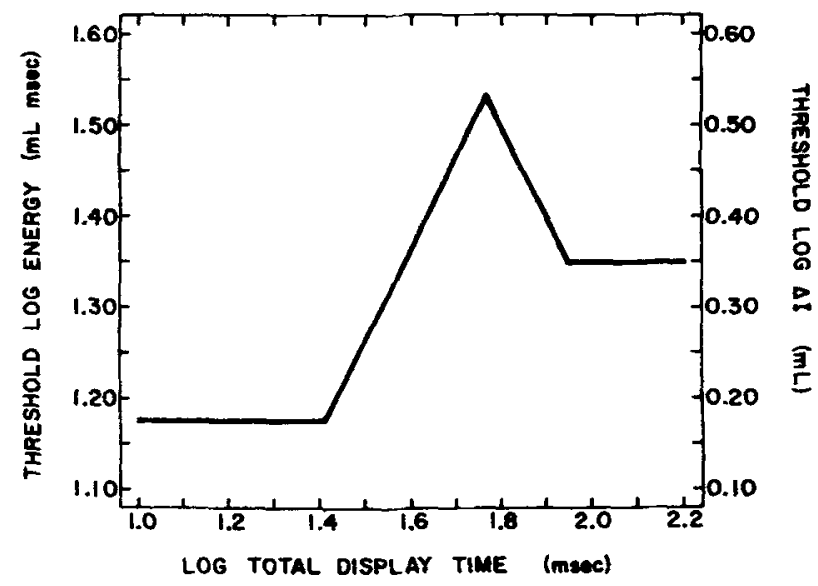

Fig. 8. Threshold energy as a function of total display time on a log tog plot. Lines based on two-fhes data obtained with background luminance of $8.91 \mathrm{~mL}$ and flash duration of $5 \mathrm{msec}$.

eventually, with an interval of about $50 \mathrm{msec}$, the center appeared dimmer than the frame. With still further increases in the interval, the two flashes were seen separately, as two distinct flashes. This again suggests what one might expect on the basis of the TEpee effect. It also suggests that the TEpee effect, or some effect similar to the TEpee effect, occurs not only at a sensation level corresponding to threshold but also at higher senation levels.

\section{LIMITATIONS OF THE TEpee EFFECT}

In the preceding sections, the generality of the TEpee effect was noted. Its limitations should also be noted. The TEpee effect appears to be limited to foveal presentations of identical flashes. At present, the relations among the variables in the peripheral retina present no clear-cut picture. The studies of Battersby and Defabaugh (1969), Bouman and Van den Brink (1952), Davy (1952), Granit and Davis (1931), Herrick (1973c), Van den Brink and Bouman (1954), however, suggest that the TEpee equations do not describe the data for peripheral stimulation. Because of the differences in the receptors, cones vs rods, there is, of course, no reason to expect that the same laws hold for both the fovea and the periphery.

Data of two-flash studies in which either the flash durations or the flash luminances differ (Battersby \& Defabaugh, 1969; Clark, 1958; Granit \& Davis, 1931; Herrick \& Theisen, 1972; Ikeda, 1965; Rashbass, 1970) are also not described by the TEpee effect. Nevertheless, the TEpee effect is compatible with models suggested to describe the interaction of nonidentical flashes (Herrick \& Theisen, 1972; Rashbass, 1970).

\section{APPENDIX}

\section{Derivations of $p$ versus i Functions from TEpee Effect}

Several steps are required to develop, from the TEpee effect, predictions of the probability of a "Yes," $p$, as a function of the interval, $i$, between the two flashes. Using a numerical example, the steps are as follows:

(a) From a TEpee plot, Fig. 8, or from raw data, obtain the threshold $\log \Delta \mathrm{I}$ associated with an interval, i. [From Fig. 8, the point at the intersection of the first two lines gives $\log \mathrm{T}=1.4138$ and threshold $\log \mathrm{E}=$ 1.1737; these values may be transformed to threshold $\log \Delta \mathrm{I}=0.1737$ and to $\mathrm{i}=15.93 \mathrm{msec}$ because $\mathrm{i}=\mathrm{T}-2 \mathrm{t}$ $=25.93-10$.

(b) Consider the threshold $\log \Delta I$ to be a $\log \Delta I$ that will be detected with a probability, p, of 0.50 (Herrick, 1967, 1969, 1970a, b, 1973b; Pollack, 1968). (Thus, when $\log \Delta \mathrm{I}=0.1737, \mathrm{p}=0.50$.)

(c) Assume that, for any given interval, $i$, the psychometric function describing $p$ as a function of $\log \Delta I$ is a cumulative normal curve; i.e., assume the phi-gamma hypothesis. (Other assumptions of the shape of the psychometric function may be made without influencing the result appreciably.) With the experimental conditions used, experimental data indicate that the standard deviation of the psychometric function is about $0.10 \mathrm{log}$ unit. Therefore, we will assume that for each interval, $i$, the psychometric function has a standard deviation of $0.10 \mathrm{log}$ unit. Based on these assumptions, plot the psychometric function for the interval, with $p=0.50$ corresponding to the threshold $\log \Delta \mathrm{l}, \mathrm{p}=0.84$ corresponding to the threshold $\log \Delta I+0.10$, etc. (In Fig. 9, for the first psychometric function on the left, for $i=15.93 \mathrm{msec}$; when $\log \Delta \mathrm{I}=0.1737, \mathrm{p}=0.50$; when $\log \Delta \mathrm{I}=0.2737$, $\mathrm{p}=0.84$, etc.)

(d) Follow Steps a, b, and c above to derive psychometric functions for several intervals. (See Fig. 9.)

(e) In the plot of psychometric functions (Fig. 9),

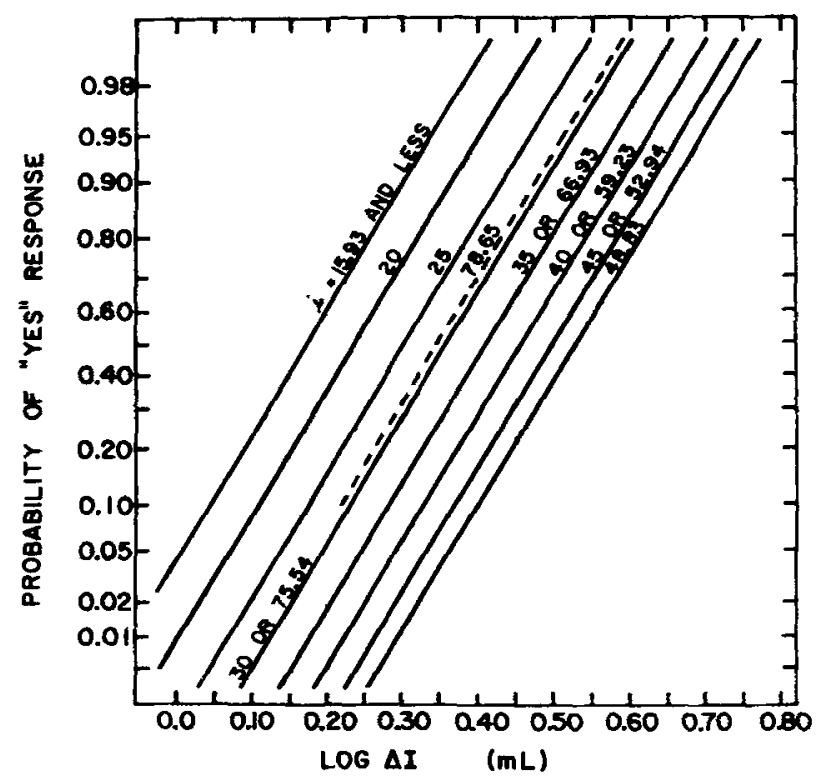

Fig. 9. Psychometric functions relating $\log \Delta I$ and $p$, the probability of a "Yes" response, for selected intervals between two 5-msec flashes. For each function, $\log \Delta t$ at $p=0.50$ is derived from Fig. 8, and the standard deviation is $0.10 \log \mathrm{mL}$. Vertical scale is a cumultive normal scale. 


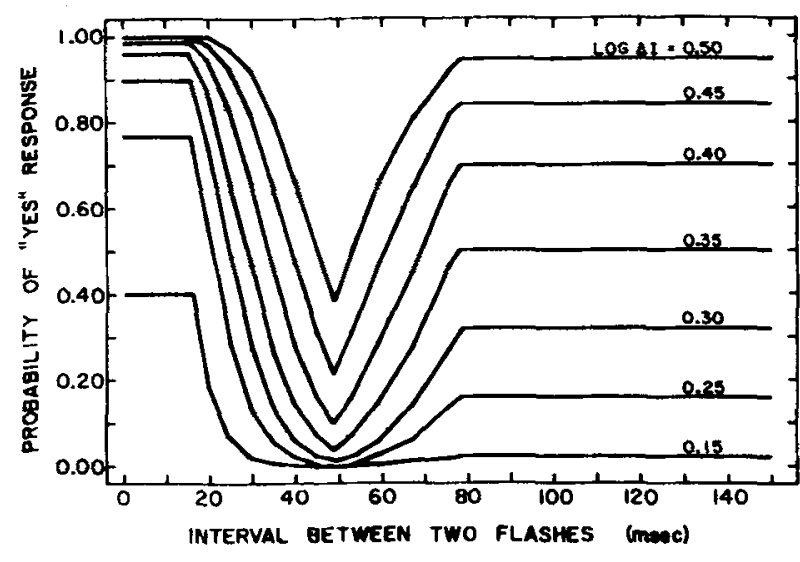

Fig. 10. Probability of a "Yes" response as a function of the interval between two identical flashes. The parameter is the luminance of the flashes, in $\log \mathrm{mL}$. Curves derived from Fig. 9.

construct a vertical at a specific $\log \Delta \mathrm{I}$. This vertical will intersect the family of psychometric functions and give, at each intersection, an interval $i$ and an associated $p$. From such pairs of values (an $i$ and a $p$ comprising a pair), a curve relating $p$ and $i$ may be drawn. A vertical constructed at some other $\log \Delta \mathrm{I}$ will intersect the family of psychometric functions at other points and yield another curve relating $p$ and i. (Based upon the plots of Fig. 9, for several $\log \Delta \mathrm{Is}$, Fig. 10 shows $\mathrm{p}$ as a function of i.) In short, based on Fig. 8, Fig. 10 shows the predicted relationships between $p$ and $i$.

(f) The sequence of operations just described may be reversed. That is, from a plot like that of Fig. 10, we can derive a plot like that of Fig. 8.

The specific aim of the above derivation was to relate the TEpee effect with the $p$ vs i functions. The analysis, however, may be generalized, because it may well apply to other visual problems in which temporal variables are manipulated. Thus, given threshold data, functions involving the probability of a "Yes" may be derived. Or, given probability of a "Yes" data, threshold functions may be derived.

\section{REFERENCES}

Battersby, W. S., \& Defabaugh, G. L. Neural limitations of visual excitability: After-ffects of subliminal stimulation. Vision Research, 1969, 9, 757-768.

Baumgardt, E., \& Bujas, Z. Sur le seuil du phosphène électrique.

L'inhibition rétroactive révélée par la méthode du double choc. Comptes Rendus de la Société de Biologie, 1951, 145, 1824-1826.

Baumgardt, E., \& Segal, J. Facilitation et inhibition. Paramètres de la fonction visuelle. L'Année Psychologie, 1942-1943. 43-44, 54-102.

Baumgardt, E., \& Segal, J. La fonction inhibitrice dans le processus visuel. Comptes Rendus de la Société de Biologie. $1946,140,231-233$.

Blackwell, H. R. Neural theories of simple visual discriminations. Journal of the Optical Society of America, 1963, 53, 129-160.

Bouman, M. A., \& Van den Brink, G. On the integrate capacity in time and space of the human peripheral retina. Journal of the Optical Society of America, 1952,42,617-620.

Clark, w C. Relations between the thresholds for single and multiple light pulses in the human eye. (Doctoral dissertation, University of Michigan) Ann Arbor, Mich: University Microfilms, 1958. No. MIC 58-7807.
Davy, E. The intensity-time relation for multiple flashes of light in the peripheral retina. Journal of the Optical Society of America, 1952, 42, 937-941.

Granit, R., \& Davis, W. A. Comparative studies on the peripheral and central retina IV. Temporal summation of subliminal visual stimuli and the time course of the excitatory after-effect. American Joumal of Physiology, 1931, 98, 644-653.

Grossberg. M. Frequencies and latencies in detecting two-flash stimuli. Perception \& Psychophysics, 1970, 7, 377-380.

Herrick, R. M. Psychophysical methodology: Comparison of thresholds of the method of limits and of the method of constant stimuli. Perceptual \& Motor Skills, 1967, 24, 915-922.

Herrick, R. M. Psychophysical methodology: Comparisons within the method of limits. Perceptual \& Motor Skills, 1969. 28, 503-514.

Herrick, R. M. Psychophysical methodology: Deductions from the phi-gamma hypothesis and related hypotheses. Perception \& Psychophysics, 1970a, 7, 73-78.

Herrick, R. M. Psychophysical methodology IV: Phi gamma hypothesis and the method of limits. Perception \& Psychophysics, 1970b, 8, 61-64.

Herrick, R. M. Increment thresholds for two identical flashes. Journal of the Optical Society of America, 1972, 62, 104-110.

Herrick, R. M. Foveal increment thresholds for multiple flashes. Journal of the Optical Society of America, 1973a, 63. 870-878.

Herrick, R. M. Psychophysical methodology VI: Random method of limits. Perception \& Psychophysics, 1973b, 13, 548-554.

Herrick, R. M. Increment thresholds for multiple identical flashes in the peripheral retina. Journal of the Optical Society of America, $1973 \mathrm{c}, 63,1261-1265$.

Herrick, R. M.. \& Theisen, C. J., Jr. Increment thresholds for two nonidentical flashes. Journal of the Optical Society of America, 1972, 62, 588-593.

Howarth, C. I. Strength duration curves for electrical stimulation of the human eye. Quarterly Journal of Experimental Psychology, 1954,6, 47-61.

Ikeda, M. Temporal summation of positive and negative flashes in the visual system. Journal of the Optical Society of America, 1965, 55, 1527-1539.

Pollack, I. Computer simulation of threshold observations by method of limits. Perceptual \& Motor Skills, 1968, 26. 583-586.

Rashbass, C. The visibility of transient changes of luminance. Journal of Physiology, 1970, 210, 165-186.

Roufs, J. A. J. Dynamic properties of vision-III. Twin flashes, single flashes and flickerfusion. Vision Research, 1973, 13, $309-323$.

Schuckman, H. \& Orbach, J. Detection thresholds as a function of the interval separation between two successive targets. Science, $1965,150,1623-1625$.

Tittarelli, R. \& Marriott, F. H. C. Temporal summation in foveal vision. Vision Research, 1970, 10, 1477-1481.

Uetsuki, T., \& Ikeda, M. Study of temporal visual response by the summation index. Journal of the Optical Society of America, 1970, 60, 377-381.

Van den Brink, G., \& Bouman, M. A. Variation of integrative actions in the retinal system: An adaptational phenomenon. Journal of the Optical Society of America, 1954, 44, 616-620.

\section{NOTE}

1. Actually, only in an earlier study (Bouman \& Van den Brink, 1952) did they present $p$ vs i plots. Most of their data were presented in plots employing an index based on $p$. The index has a value of 1.0 when the two flashes occur simultaneousiy, and 0.0 when the two flashes are widely separated in time. Bouman and Van den Brink's index may be written as follows: Index $=-\left[P_{\infty} /\left(P_{0}-P_{\infty}\right)\right]+\left[1 /\left(P_{0}-P_{\infty}\right)\right] p_{1}$ where $P$ is the probability of a "Yes" with two flashes separated by a very long interval, $p$ is the probability of a "Yes" with two flashes at a particular interval. For the data "Yes" with two flashes at a particular interval. For the data of any one session, $P_{0}$ and $P_{\infty}$ are constants, and the equation relating the index and $p$ is simply the equation of a straight line, with an intercept of $-\left[P_{\infty} /\left(P_{0}-P_{\infty}\right)\right]$ and a slope of $\left[1 /\left(\mathbf{P}_{o}-\mathbf{P}_{\infty}\right)\right]$.

(Received for publication July 6, 1973; revision received Novem ber 5,1973 .) 